\title{
Food Industry Self-Regulation and the Role of the Government
}

\author{
Mamoru Miyamoto ${ }^{1} \&$ Yayoi Tanaka ${ }^{2}$ \\ ${ }^{1}$ Department of Economics, Kanto Gakuin University, Yokohama, Japan \\ ${ }^{2}$ Department of Health and Nutrition Sciences, Faculty of Human Health, Komazawa Women's University, Inagi, \\ Japan \\ Correspondence: Mamoru Miyamoto, 1-50-1 Mutsuurahigashi, Kanazawa-ku, Yokohama, Japan. Tel: \\ 81-45-781-2001. E-mail: miya@kanto-gakuin.ac.jp
}

Received: April 29, 2015 Accepted: May 26, 2015 Online Published: July 30, 2015

doi:10.5539/ijms.v7n4p1 URL: http://dx.doi.org/10.5539/ijms.v7n4p1

\begin{abstract}
This study investigates the effectiveness of food industry self-regulation. We examine the role of government in support of industry self-regulation and the possibility of a conjoined effort to ensure that susceptible young viewers are protected from deceptive television commercials that exacerbate the threat of childhood obesity. We argue that the food industry should have the authority to regulate television commercials, and the role of the government in this context should be restricted to proposing time limits for television commercials based on scientific evidence and the monitoring and supervising of food industry compliance. We emphasize that what matters for the success of self-regulation is not whether the credibility of the penalty scheme is guaranteed, but how the penalty scheme can guarantee an incentive for each food company to not violate self-regulation given government support. Additionally, consumer trust in a food industry self-regulation system depends on the level of government support. Less restrictive performance of the government might lead to a decrease in consumer confidence that would undermine industry self-regulation efforts. Therefore, we conclude that a mixed system in which both the government and the food industry participate is desirable for the protection of children from deceptive television commercials.
\end{abstract}

Keywords: childhood obesity, food industry, government regulation, monitoring, self-regulation, television commercials

\section{Introduction}

Childhood obesity is a significant societal problem in Western countries. This condition has been linked to food and beverage industry television commercials that influence children who are susceptible and vulnerable to marketers. Substantial research from fields such as marketing, education, law, medicine, and nutrition has developed arguments concerning the shielding of children from deceptive television commercials. Three main solutions have been proposed.

The first is self-regulation by the food industry; that is, the industry should curtail the danger of childhood obesity through responsible advertising and other measures. The second is government regulation, which is considered the most effective tool because compliance is legally enforceable. The third is consumer socialization, which has been discussed in the extant literature from a consumer's perspective. Several prior studies address consumer socialization, particularly in the marketing field (e.g., Carlson \& Grossbart, 1988; Miyamoto, 2015; Moschis, 1985; Rose, 1999; Ward, 1974); therefore, we do not discuss this topic extensively in this study. Our research interest is limited to the first two regulatory tools. Using a simple but useful model, we investigate (1) what type of penalty scheme the food industry requires for self-regulation to operate effectively, (2) why government regulation is ineffective, and (3) the government's possible supporting role in industry self-regulation if government regulation is not necessary.

We emphasize that the food industry should engage in industry self-regulation to control advertising activity; however, the government should perform some essential functions to promote compliance, in particular, enforcing time limits on television commercials based on scientifically reinforced standards, monitoring, and supervising. We suggest that the central role of the government should be restricted to a supplementary role that supports self-regulation. Additionally, we argue that the design of the penalty scheme is the most salient factor in the success of self-regulation and not the guarantee of the credibility of the penalty scheme because the 
credibility of the penalty scheme is attached to the self-regulation system given the government support. However, consumer trust in industry self-regulation depends on the level of government support. Less restrictive performance of the government would lead to a decrease in consumer confidence, thereby undermining self-regulation. This implies that although the credibility of the penalty scheme is automatically guaranteed, consumer trust in industry self-regulation itself needs government support. The difference is the distinction between the penalty scheme and the industry self-regulation system. The penalty scheme or penalty rule is a component of self-regulation; that is, self-regulation is composed of the penalty rule (the major framework), government monitoring, and supervising. Thus, we conclude that a mixed system in which both the government and the food industry participate is desirable to protect children from deceptive television commercials.

\section{Literature Review}

\subsection{Is Self-regulation Effective?}

Garvin (1983) classifies industry self-regulation into two types: (1) self-regulation that benefits only some members of the industry at the expense of others and (2) self-regulation that benefits all of the participants. Garvin (1983) emphasizes that self-regulation including voluntary product standards and occupational licensing leads to the exclusion of new market entrants, which negatively affects national welfare; however, standards and occupational licensing ensure that products meet minimum quality levels. Garvin (1983) concludes that mixed systems "combining industry standards setting with government oversight" are most desirable as a policy option (p. 37). Galbraith-Emami and Lobstein (2013) survey a large number of papers published in peer-reviewed journals to determine whether children's exposure to the promotion of unhealthy food and beverage products was reduced after the introduction of industry self-regulation or government regulation. The authors conclude that companies' self-regulation efforts are unlikely to have the desired effects without adequate government monitoring. Wescott, Fitzpatrick, and Phillips (2012) insist that industry self-regulation can be "a valuable tool in improving public health outcomes" if there is "transparent and independent" monitoring support (p. 1928). Boddewyn (1989) highlights the need for a "proper combination of societal controls" (p. 27). Our conclusion is fundamentally similar to the conclusions of prior researchers.

Sharma, Teret, and Brownell (2010) summarize the history of self-regulation in various industries with a focus on the success and failure of self-regulation. The authors identify the necessary conditions for self-regulation to work effectively, one of which is the requirement of standards to earn societal trust. Gupta and Lad (1983) report that smaller companies would prefer direct governmental regulation rather than self-regulation if the self-regulation standards benefit companies that are stronger (that is, companies with more influence). In such contexts, self-regulation fails. Wilde (2009) argues that the success of self-regulation depends on the participation of leading food and beverage companies. Pomeranz (2010) notes that the Federal Trade Commission (FTC) has proven the ineffectiveness of self-regulation, which has led to growing recognition of the need for government regulation.

\subsection{Consumer Socialization}

Consumer socialization is not related to self-regulation and government regulation. However, we briefly address consumer socialization. Ward (1974) defines consumer socialization as the process "by which young people acquire the skills, knowledge, and attitudes relevant to their functioning as consumers in the market place" (p. 2). Subsequently, this argument has been rigorously developed in various research fields, particularly in marketing. The role of parents as consumer socialization agents has been emphasized from several perspectives: parent-child relations, parent-child interaction, family communication, and parent-company interaction (e.g., Carlson, Grossbart, \& Stuenkel, 1992; Moschis, 1985; Özmete, 2009; Miyamoto, 2015). Although the significance of consumer socialization is fully recognized, it is unlikely to contribute to a rapid reduction in the threat of childhood obesity to a greater extent than self-regulation. Therefore, we do not explore consumer socialization further in this study.

\section{Model}

\subsection{Basic Framework}

We present a simple model to explain how effectively self-regulation works in the food industry and the type of role that governments play in this context. Although we focus on self- regulation of the food industry as a whole, the research objects are individual food companies that are members of "self-regulation organizations," such as the Advertising Self-Regulation Council (ASRC) in the US and the European Advertising Standards Alliance (EASA) in Europe. Therefore, we focus on the behavior of an individual food company to examine the 
effectiveness of the penalty scheme of food industry self-regulation, particularly in terms of time-length restrictions on television commercials.

A food company functions as a supplier of food products and as an advertiser who creates television commercials targeted at children to promote demand for food products. The demand for food products $D$ depends on the amount of television commercials $x . x$ is expressed by the time length such as minutes per hour. However, it is plausible that in our model, $x$ is measured by the monthly unit (e.g., hours per month) associated with the monthly profits of a food company. Equation (1) shows the demand function,

$$
D=D(x),
$$

where $D^{\prime}(x)>0$, and $D^{\prime \prime}(x)<0$.

These two assumptions imply that although the demand for food products increases with the amount of commercials $x$, the rate of the increase in demand varies inversely with $x$. As this market is perfectly competitive, the price of the food products $p$ is given for each food company. Additionally, a food company supplies the product amounts that correspond to demand $D(x)$. Therefore, the revenue function $R$ of each food company ultimately depends on $x$, and is shown in equation (2):

$$
R(x)=p D(x),
$$

where it is assumed that

$R^{\prime}(x)>0$, and $R^{\prime \prime}(x)<0$.

All costs $C$ consist of two elements: food production costs and the cost of product advertising to children via television commercials. The latter cost depends on the amount of television commercials $x$, and is defined by $C(x)$

where $C^{\prime}(x)>0 ; C^{\prime \prime}(x)>0$.

In contrast, because the former cost is independent of $x$, it is assumed to be constant, $\bar{C}$. Additionally, our model standardizes $\bar{C}$ to be zero without loss of generality; therefore, $\bar{C}$ is no longer considered. Equation (3) shows a food company's profit function without sanction.

$$
\pi_{n}=R(x)-C(x)
$$

We assume that every food company is homogeneous and has the same properties; that is, we assume that the revenue function, cost function, and the profit function are identical for all food companies.

\subsection{Commercial Time Limits}

We consider the restriction that the government imposes limits on the length of television commercials, regardless of whether the system involved is self-regulating or government regulating. This restriction is referred to as "commercial time limits," defined by $\bar{x}$ in our model. Commercial time limits define the maximum length of television commercials allowed during children's programs; food companies must comply with this standard when targeting children in advertising. This standard must be based on scientific evidence, particularly evidence from the nutrition and medical perspectives. Moreover, it is essential that consumers and the food industry agree that the standard $\bar{x}$ is appropriate. If all parties are not satisfied with this standard, complaints about the standard will persist and the companies would have little incentive to comply with the standard. This is the reason for government-restricted commercial time limits $\bar{x}$.

In the US, the Children's Television Act (CTA) authorized the FTC to enforce hourly limits of " 10.5 minutes per hour on weekends and 12 minutes per hour on weekdays" (Centers for Disease Control and Prevention [CDC], 2012 , p. 1). If a food company violates the code and exceeds the limit $\bar{x}$, fines are imposed on the company based on the amount of commercials that exceed the limit $\bar{x}$ (see Section 4.1).

In addition to commercial time limits, some restrictions on the content of television commercials are required. The EU has established nutrition criteria for food and beverage advertising to children and has requested the food and beverage industries to follow the criteria (EU Pledge, 2012). Because the focus of this study is the amount of television commercials, we do not discuss further the legislation related to advertising content. Our model assumes that all of the television commercials aired meet the required nutrition criteria.

\section{Food Industry Self-Regulation}

This section investigates a case where the food industry engages in self-regulation to respond to consumer claims. We examine how the scheme of self-regulation (that is, the "code") should be developed by the food industry. The responsibility of developing the code is delegated to a specific membership-based organization such as the 
ASRC in the US or the EASA in Europe. We refer to the food industry as the authoritative body that is responsible for industry self-regulation.

\subsection{Penalty Rule}

Effective self-regulation depends on the penalty rule designed by the food industry. An adequate penalty rule provides a level of incentive sufficient to encourage food company compliance with the code. The penalty rule is designed as follows.

The fines imposed should be proportional to the extent to which the food company exceeds the commercial time limits $\bar{x}$. The fine $F$ is calculated as the difference between the commercial time limits $\bar{x}$ and the actual amount of television commercials that a food company has aired multiplied by the "penalty rate" $\alpha$, where $\alpha(\geq 0)$. Thus,

$$
F=\alpha(x-\bar{x})
$$

where $x \geq \bar{x}$.

The evaluation method of the amount of the fine imposed is significant. Although this evaluation is straightforward, the introduction of the penalty rate $\alpha$ is persuasive and tractable in our framework.

If a food company violates the code by airing television commercials $x$ that exceeds the limit $\bar{x}$, the food company's profit function with sanctions is expressed by equation (5):

$$
\pi_{s}=R(x)-D(x)-\alpha(x-\bar{x}) .
$$

In contrast, equation (6) shows the profit function $\bar{\pi}$ of a food company that stays at the limit $\bar{x}$ :

$$
\bar{\pi}=R(\bar{x})-C(\bar{x})
$$

The condition presented in equation (7) is necessary for effective and sustainable self-regulation.

$$
R(\bar{x})-C(\bar{x})=R(x)-D(x)-\alpha(x-\bar{x})
$$

Equation (7) implies that a food company is indifferent between complying with the code and violating it by providing viewers an excessive amount of television commercials $x$ over the limit $\bar{x}$. This implication shows that the penalty rate $\alpha$ should be determined at a level that will remove the incentive for food companies to violate the commercial time-length restriction. We refer to this penalty rate $\alpha$ as the "threshold penalty rate" denoted by $\overline{\bar{\alpha}}$.

Equation (7) represents the relationship between the threshold penalty rate and the amount of television commercials aired. Equation (8) clarifies this relationship.

$$
\overline{\bar{\alpha}}=\frac{\{R(x)-C(x)\}-\{R(\bar{x})-C(\bar{x})\}}{x-\bar{x}}
$$

Equation (8) shows the design of the penalty scheme; that is, the relationship between $\overline{\bar{\alpha}}$ and $x$, given the commercial time limits $\bar{x}$. The effectiveness of the regulation depends on the formation of the pair $(x, \overline{\bar{\alpha}})$ given $\bar{x}$. The differentiation of $\overline{\bar{\alpha}}$ with regard to $x$ determines the shape of the combination shown in Figure1.

$$
\overline{\bar{\alpha}}^{\prime}(x) \equiv \frac{\partial \overline{\bar{\alpha}}}{\partial x}=\frac{\left\{R^{\prime}(x)-C^{\prime}(x)\right\}(x-\bar{x})-[\{R(x)-C(x)\}-\{R(\bar{x})-C(\bar{x})\}]}{(x-\bar{x})^{2}}
$$

Lemma 1 is presented to illustrate Figure1.

Lemma 1: Equation (8) has at least one solution $x_{m}$ satisfying $\overline{\bar{\alpha}}^{\prime}\left(x_{m}\right)=0$ at the interval $\left[\bar{x}, x_{n}\right]$, where $x_{n}$ meets $R^{\prime}(x)=C^{\prime}(x)$, which is the first-order condition for maximization in the absence of sanctions.

Proof: The value of the partial derivative (9) becomes infinity as $x$ approaches $\bar{x}$, that is, $\lim _{x \rightarrow \bar{x}} \overline{\bar{\alpha}}^{\prime}(x)=\infty$. This implies that in the space $(x, \overline{\bar{\alpha}})$, a curve depicted by (8) has the slope $\infty$ of at $\bar{x}$.

A food company's profit without sanctions $\pi_{n}$ becomes maximum at $x_{n}$; subsequently, $\pi_{n}$ decreases while $x-\bar{x}$, which represents a portion of the fine, increases with an increase in $x$. The threshold penalty rate $\overline{\bar{\alpha}}$ can be deduced using this information. Thus, $\overline{\bar{\alpha}}^{\prime}(x)<0$ at $x_{n}$.

\subsection{Iso-Profit Curve}

Figure 1 illustrates the combinations of $x$ (the actual amount of television commercials) and $\overline{\bar{\alpha}}$ (the penalty rate that makes a food company indifferent between complying with self-regulation and violating the rule). We shall refer to this curve as the "iso-profit curve." This section examines the iso-profit curve in detail. As long as the amount of television commercials $x$ is less than $\bar{x}$ (the commercial time limits), no penalty is charged. However, a food company has no incentive to offer $x$ less than $\bar{x}$. If a food company offers an amount of television 
commercials $x_{A}$ (in Figure 1) by violating the rule, a fine amounting to $\overline{\bar{\alpha}}_{A}\left(x_{A}-\bar{x}\right)$ would be imposed based on the penalty rule, which ensures that the food company's profit by providing $x_{A}$ is identical to that at $\bar{x}$. Therefore, compliance is ensured because there is no incentive for a company to violate the rule. We assume that a food company prefers to stay at $\bar{x}$ rather than exceed the commercial time limits, because although the two options (that is, staying at $\bar{x}$ and exceeding it) are theoretically indifferent for each food company, the latter actually affects consumers. Specifically, violating the rule causes poor health in children. This assumption helps ensure the credibility of the penalty scheme (discussed later in this section). With regard to $x_{n}$, each food company would determine the maximum amount of commercials at $x_{n}$ without penalty. It is plausible that all food companies would desire to set their targets at $x_{n}$. However, the curve configuration indicates that the profit optimization argument does not necessarily hold in the case of self-regulation because of the penalties (which take $x-\bar{x}$ into account).

Unlike the scheme explained by the points on the iso-profit curve, if a penalty rate $\overline{\bar{\alpha}}_{B}$ is offered for $x_{A}$ at point $B$, a food company would be willing to violate the rule because the incurred losses would be smaller by $\left(\overline{\bar{\alpha}}_{A}-\overline{\bar{\alpha}}_{B}\right)\left(x_{A}-\bar{x}\right)$ than the losses brought by the penalty rule. $\left(\overline{\bar{\alpha}}_{A}-\overline{\bar{\alpha}}_{B}\right)\left(x_{A}-\bar{x}\right)$ is calculated as the difference between the amount of penalty represented by $\overline{\bar{\alpha}}_{A}\left(x_{A}-\bar{x}\right)$ in accepting the penalty rule at point $A$ and the amount of penalty represented by $\overline{\bar{\alpha}}_{B}\left(x_{A}-\bar{x}\right)$ in choosing point $B$. This implies that violators can always gain excessive profits by choosing point $B$ compared to the companies that stay at $\bar{x}$. Therefore, food companies are encouraged to exceed the specified amount of television commercials. This applies to every point located in the inner area of the iso-profit curve.

One might doubt whether the food industry discloses the true penalty rule; that is, the true iso-profit curve. If the actual (but false) iso-profit curve (e.g., the curve running through point $B$ ) is announced (which is set below the true curve depicted in Figure 1), consumers might believe that it is rational for the food companies to declare point $B$. However, the earlier assumption shows that such a choice by food companies is unusual, and the consumers can see that the penalty scheme disclosed by the food industry is false. Although this explanation depends on the earlier assumption, such a mechanism would be inherent in the market itself. Thus, we find that the formation of the penalty scheme ensures the credibility given the involvement of the government (see Section 5). We next examine point $C$, where $\overline{\bar{\alpha}}_{m}$ is offered for $x_{A}$. At this point,there is an incentive for food companies to refrain from providing $x_{A}$ because they must pay an excessive penalty over the fine imposed according to the penalty rule at $x_{A}$ by $\left(\overline{\bar{\alpha}}_{m}-\overline{\bar{\alpha}}_{A}\right)\left(x_{A}-\bar{x}\right)$.

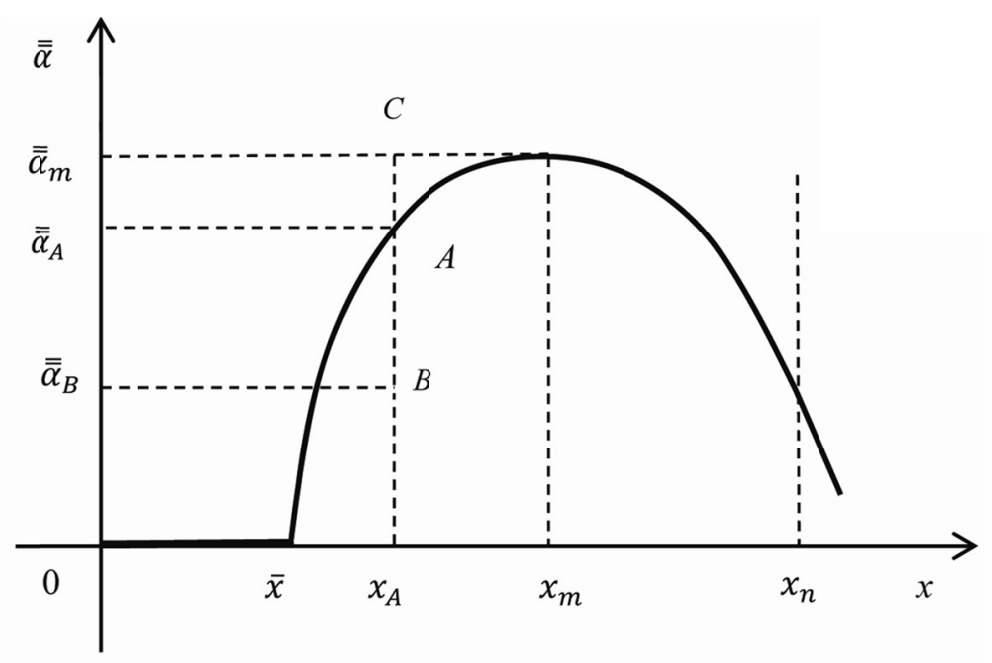

Figure 1. Property of the iso-profit curve

\section{The Role of the Government}

\subsection{Government Regulation}

What is the central role of the government in protecting children from childhood obesity, specifically, in the context of food and beverage television advertising? Section 3.2 explains that one significant task is to set commercial time limits, irrespective of whether the restriction represents self-regulation or government regulation. This section discusses whether government regulation is more effective than self-regulation in the 
context of the food industry. If government regulation is unnecessary, what level of involvement should the government assume with respect to food industry self-regulation? Initially, we insist that government regulation is unnecessary if food industry self-regulation is in place. In this case, the role of the government should be restricted to supporting food industry self-regulation. In the absence of industry self-regulation, the government should design a penalty scheme similar to that presented in Section 4. However, it might be impossible for the government to define a more accurate and stricter penalty scheme than that defined by the industry because of the asymmetric information between the food industry and the government.

We consider a case where the government offers penalty rates that are independent of the amount of television commercials that the food companies provide given the commercial time limits $\bar{x}$ and the iso-profit curve illustrated in Figure 2. The crucial difference between government regulation and industry self-regulation is that the penalty rates that the government offers do not depend on the amount of television commercials $x$. The penalty rule that the government proposes consists of the commercial time limits $\bar{x}$ and fines $\overline{\bar{\alpha}}_{G}(x-\bar{x})$ for noncompliance. These penalties are compulsory, not autonomous.

In Figure 2, when the government offers $\overline{\bar{\alpha}}_{G}$, the response of the food company is to behave between $x_{C}$ and $x_{D}$.It is most desirable in this case for the food company to choose $x_{m}$ because at $x_{m}$, the company can earn the highest excess profits of $\left(\overline{\bar{\alpha}}_{m}-\overline{\bar{\alpha}}_{G}\right)\left(x_{m}-x_{C}\right)$. This result indicates the flaw in this penalty scheme: the penalty scheme aggravates the situation by providing an incentive for the food company to exceed the commercial time limits. In contrast, setting $\tilde{\alpha}_{G}$ above $\overline{\bar{\alpha}}_{m}$ appears the optimal decision to discourage food companies from violating the law because food companies must accept large disciplinary losses of at least $\left(\tilde{\alpha}_{G}-\overline{\bar{\alpha}}_{m}\right)(x-\bar{x})$ at any $x$. However, the result is contrary to expectations. The statutory penalty rates $\tilde{\alpha}_{G}$ have the opposite effect on food companies than expected; that is, food companies prefer to increase the amount of television commercials to $x_{m}$ rather than remain at $\bar{x}$. The reason is as follows. Consider a case where, inadvertently, a food company has exceeded the commercial time limits $\bar{x}$ by a small amount (e.g., $\left.x_{C}\right)$. The food company would increase the amount of television commercials to $x_{m}$ if the losses of $\left(\tilde{\alpha}_{G}-\overline{\bar{\alpha}}_{G}\right)\left(x_{C}-\bar{x}\right)$ are larger than the losses of $\left(\tilde{\alpha}_{G}-\overline{\bar{\alpha}}_{m}\right)\left(x_{m}-\bar{x}\right)$. Thus, we conclude that the government cannot design a perfect scheme for government regulation, especially with regard to the penalty rule.

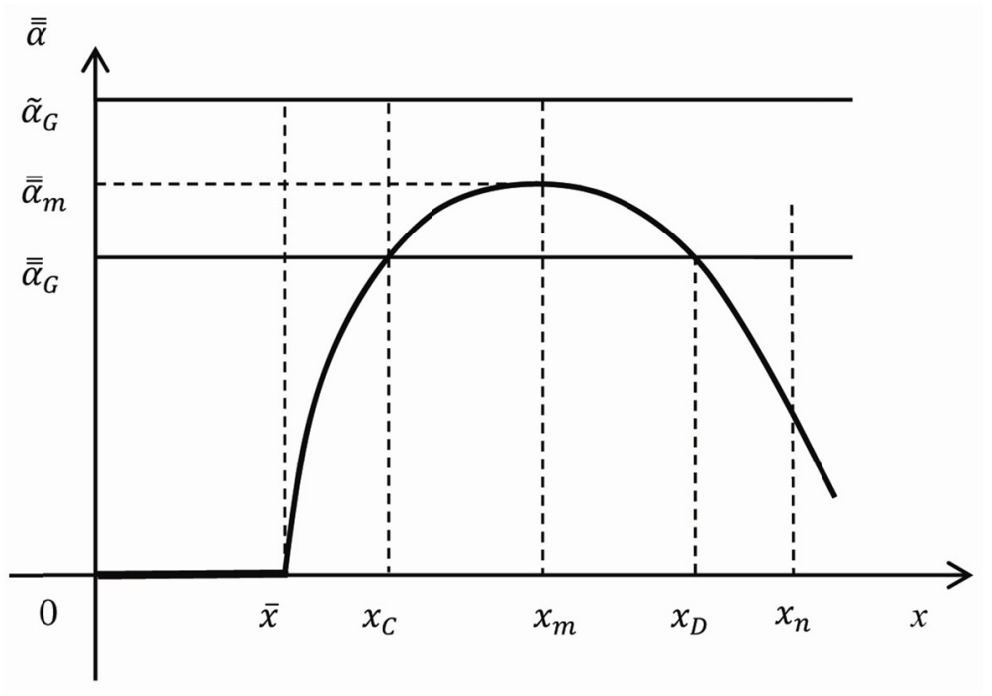

Figure 2. The case of government regulation

\subsection{Monitoring and Supervision}

With respect to industry self-regulation, penalties must be applied according to the rules described earlier if the amount of television commercials aired by the food companies exceeds the limit. We have not fully considered who identifies the violator(s), and how the fines are calculated. Although the government has full information on commercial time limits, it cannot recognize the type of profit function that each company obtains. This information entirely belongs to the food industry. Therefore, although the government can easily identify who violated the rule, the government cannot estimate the extent to which the violator exceeds the time length restrictions. Thus, the role of the government is limited to monitoring and supervising the food companies' compliance with the system. In contrast, the food industry cannot assume the monitoring and supervisory role 
instead of relying of the government. We believe that this is because consumers cannot trust the industry or the organization to which the industry delegates the responsibility. This assumption, which may be accurate, convinces us that the success of industry self-regulation depends on the extent of government involvement in industry self-regulation (in the form of monitoring and supervision).

\section{Conclusion}

The model presented in this study shows that although food industry self-regulation is effective only with the government involvement, government regulation cannot necessarily provide an incentive for food companies to fully comply with the regulation. With respect to the time length restrictions on television commercials, the penalty rule (except the commercial time limits) already has the property of scheme credibility. Therefore, the food industry self-regulation scheme would ensure the condition in terms of the penalty rule. The commercial time limits, monitoring, and supervision represent the central role of the government. It is apparent that these government roles are inevitable in government regulation as well as in industry self-regulation. We emphasize that the effectiveness of food industry self-regulation depends on the extent of government involvement.

Our study has some limitations. In our model, we assume that the food industry can easily implement industry self-regulation. However, as Gupta and Lad (1983) noted, unless industry self-regulation benefits each company that is planning to participate in the system, the system would not succeed. Additionally, the assumption related to the food companies' homogeneity is controversial. If this assumption were not applied to our model, the diversity of the iso-profit curve would make our arguments more complex. We focus only on time length restrictions on television commercials. Including the content of television commercials as one of the regulation targets might change the role of government from the role discussed in this study. These factors need to be addressed in future research. Finally, we do not discuss a reflective comparison of the effect of television commercials and other media such as Internet in the food industry. This issue will be addressed in our future research.

\section{Acknowledgement}

We would like to thank Editage (www.editage.jp) for English language editing.

\section{References}

Boddewyn, J. J. (1989). Advertising self-regulation: True purpose and limits. Journal of Advertising, 18(2), 19-27. http://dx.doi.org/10.1080/00913367.1989.10673148

Carlson, L., \& Grossbart, S. (1988). Parental style and consumer socialization of children. Journal of Consumer Research, 15(1), 77-94. http://dx.doi.org/10.1086/209147

Carlson, L., Grossbart, S., \& Stuenkel, J. K. (1992). The role of parental socialization types on differential family communication patterns regarding consumption. Journal of Consumer Psychology, 1(1), 31-52. http://dx.doi.org/10.1016/S1057-7408(08)80044-7

Centers for Disease Control and Prevention (CDC). (2012). Nutrition advertising targeting children. Public Health Law Program, 1-5. Retrieved from http://www.cdc.gov/winnable/advertising_children.html

EU Pledge. (2012). Nutrition criteria white paper. Retrieved from http://www.eu.pledge.eu/

Galbraith-Emami, S., \& Lobstein, T. (2013). The impact of initiatives to limit the advertising of food and beverage products to children: A systematic review. Obesity Reviews, 14(12), 960-974. http://dx.doi.org/10.1111/obr.12060

Garvin, D. A. (1983). Can industry self-regulation work? California Management Review, 25(4), 37-52. http://dx.doi.org/10.2307/41165031

Gupta, A. K., \& Lad, L. J. (1983). Industry self-regulation: An economic, organizational, and political analysis. Academy of Management Review, 8(3), 416-425. http://dx.doi.org/10.5465/AMR.1983.4284383

Miyamoto, M. (2015). The influence of parental concern on food companies' marketing strategies. International Journal of Marketing Studies, 7(1), 15-23. http://dx.doi.org/10.5539/ijms.v7n1p15

Moschis, G. P. (1985). The role of family communication in consumer socialization of children and adolescents. Journal of Consumer Research, 11(4), 898-913. http://dx.doi.org/10.1086/209025

Özmete, E. (2009). Parent and adolescent interaction in television advertisements as consumer socialization agents.Education, 129 (3), 372-381. Retrieved from http://eric.ed.gov/?id=EJ871577

Pomeranz, J. L. (2010). Television food marketing to children revisited: The Federal Trade Commission has the 
constitutional and statutory authority to regulate. The Journal of Law, Medicine \& Ethics, 38(1), 98-116. http://dx.doi.org/10.1111/j.1748-720X.2010.00470.x

Responsible Advertising and Children. (2015). Some facts about advertising self-regulation, 1-4. Retrieved from http://www.responsible-advertising.org/selfregulation.asp

Rose, G. M. (1999). Consumer socialization, parental style, and developmental timetables in the United States and Japan. Journal of Marketing, 63(3), 105-119. http://dx.doi.org/10.2307/1251778

Sharma, L. L., Teret, S. P., \& Brownell, K. D. (2010). The food industry and self-regulation: Standards to promote success and to avoid public health failures. American Journal of Public Health, 100(2), 240-246. http://dx.doi.org/10.2105/AJPH.2009.160960

Ward, S. (1974). Consumer socialization. Journal of Consumer Research, 1(2), 1-14. http://dx.doi.org/10.1086/208584

Wescott, R. F., Fitzpatrick, B. M., \& Phillips, E. (2012). Industry self-regulation to improve student health: Quantifying changes in beverage shipments to schools. American Journal of Public Health, 102(10), 1928-1935. http://dx.doi.org/10.2105/AJPH.2011.300610

Wilde, P. (2009). Self-regulation and the response to concerns about food and beverage marketing to children in the United States. Nutrition Reviews, 67(3), 155-166. http://dx.doi.org/10.1111/j.1753-4887.2009.00183.x

\section{Copyrights}

Copyright for this article is retained by the author(s), with first publication rights granted to the journal.

This is an open-access article distributed under the terms and conditions of the Creative Commons Attribution license (http://creativecommons.org/licenses/by/3.0/). 